\title{
Características do pasto e acúmulo de forragem em capim-tanzânia submetido a alturas de manejo do pasto
}

\author{
Marcos Weber do Canto(1), Clóves Cabreira Jobim(1), Eliane Gasparino(1) e André Ricardo Hoeschl(1)
}

(1)Universidade Estadual de Maringá, Departamento de Zootecnia, Avenida Colombo, no 5.790, CEP 87020-900 Maringá, PR.
E-mail: mwcanto@uem.br, ccjobim@uem.br, egasparino@uem.br, decozoo@yahoo.com

Resumo - O objetivo deste experimento foi avaliar alturas de manejo do pasto $(20,40,60$ e $80 \mathrm{~cm})$ em capimtanzânia (Panicum maximum Jacq.), em regime de lotação contínua, nas características do dossel e acúmulo de matéria seca. Os animais utilizados foram novilhos Nelore (Bos indicus), e a taxa de lotação foi variável. Foram avaliados: a massa de forragem, a massa de lâmina de folha verde, a razão folha:colmo, a composição morfológica e a taxa de acúmulo de matéria seca. O delineamento experimental foi inteiramente casualizado, com duas repetições. A massa de forragem aumentou linearmente com o aumento da altura do pasto. As médias de massa de forragem foram 2.767, 3.105, 3.657 e $4.436 \mathrm{~kg} \mathrm{ha}^{-1}$, respectivamente, para as alturas de 20, 40, $60 \mathrm{e} 80 \mathrm{~cm}$. As taxas de acúmulo de matéria seca, a 20,40,60 e $80 \mathrm{~cm}$, foram, respectivamente, 104, 108, 90 e $81 \mathrm{~kg} \mathrm{ha}^{-1}$ por dia, o que indica que houve redução dessas taxas com a elevação da altura do pasto. A razão folha:colmo decresceu linearmente com o aumento da altura do pasto. Pastagens de capim-tanzânia, sob lotação contínua ao final da primavera e durante o verão, devem ser utilizadas entre 40 e $60 \mathrm{~cm}$ de altura.

Termos para indexação: Panicum maximum, altura do dossel, componentes morfológicos, manejo do pastejo.

\section{Sward characteristics and herbage accumulation of Tanzania grass submitted to sward heights}

\begin{abstract}
The objective of this experiment was to evaluate different sward height $(20,40,60$ e $80 \mathrm{~cm})$ in Tanzania grass (Panicum maximum Jacq.) pastures managed under continuous stocking. The animals used were Nellore steers, and the control of sward height was done with put-and-take techniques. Evaluations were made for: forage mass, green leaf mass, leaf:stem ratio, morphological composition and dry matter accumulation rate. The experimental design was completely randomized with two replications. Forage mass increased linearly with sward height with overall mean of 2,767,3,105, 3,657 and 4,436 $\mathrm{kg} \mathrm{ha}^{-1}$ at sward heights $20,40,60$ and $80 \mathrm{~cm}$, respectively. Rates of dry matter accumulation decreased with increasing sward heights and were 104, 108, 90 and $81 \mathrm{~kg} \mathrm{ha}^{-1}$ per day for sward heights $20,40,60$ and $80 \mathrm{~cm}$, respectively. Leaf:stem ratio decreased linearly with sward heights. Tanzania grass pastures, under continuous stocking, should be managed between 40 and $60 \mathrm{~cm}$ heights in the final of spring and during summer station.
\end{abstract}

Index terms: Panicum maximum, canopy height, morphological components, grazing management.

\section{Introdução}

A criação de gado de corte na Região Sul do Brasil apresenta baixos índices de produtividade (Nabinger et al., 2000). Nas fazendas, o manejo do pastejo recebe pouca atenção, e os solos das pastagens destinadas à pecuária de corte, na maioria das situações, apresentam baixa fertilidade (Moraes et al., 2002). Entre as alternativas para se alterar esse contexto estão as melhorias do manejo do pastejo e das condições de fertilidade dos solos.
O capim-tanzânia foi liberado em 1990 pelo Centro Nacional de Pesquisa de Gado de Corte, em conjunto com outras instituições de pesquisa, e apresenta alta participação de folhas na matéria seca e elevado rendimento de forragem (Jank, 1995). As características do pasto podem ser descritas pela quantidade de massa de forragem, de massa de folha verde, massa de forragem verde, composição morfológica, índice de área foliar, altura do dossel, composição botânica e a razão folha:colmo. Resultados que definem as relações da massa de forragem, da massa de lâmina de folha verde 
e da massa de forragem verde com a altura do pasto, para pastagens de capim-tanzânia usadas sob lotação contínua, são raros na literatura. Os experimentos de pastejo de Brâncio et al. (2003), Mello \& Pedreira (2004) e Barbosa et al. (2007) avaliaram as características do pasto da cultivar Tanzânia-1, sob regime de desfolhação intermitente.

As condições das pastagens são responsivas a fatores de meio ambiente como o clima, condições do solo, a características genéticas de plantas, a populações de animais e fertilizantes e ao manejo principalmente (Hodgson, 1985). A altura do dossel forrageiro em pastos de 'Mombaça' e 'Tanzânia-1' de Panicum maximum, sob lotação intermitente, pode modificar características morfológicas do dossel, as perdas e a produção de forragem (Silva, 2004). Estudo conduzido nas condições do inverno do Noroeste do Paraná mostrou que a altura do pasto, usada em capim-tanzânia, influenciou no desempenho individual de novilhos da raça Nelore (Canto et al., 2002). As forrageiras podem modificar a arquitetura do dossel em resposta à desfolhação (Marriot \& Carrère, 1998; Palhano et al., 2005). A procura, a preensão e a taxa de consumo de forragem, pelos animais em pastejo, são influenciadas pelo arranjo espacial e estrutural do dossel (Prache et al., 1998; Palhano et al., 2005). O consumo de forragem é positivamente correlacionado à altura do pasto, à razão folha:colmo, à disponibilidade de forragem total e à massa de forragem verde, em pastos de capim-tanzânia sob lotação intermitente (Gontijo-Neto et al., 2006).

O objetivo deste trabalho foi avaliar as características do dossel forrageiro e o acúmulo de forragem, em pastagens de capim-tanzânia, sob lotação contínua, submetidas a diferentes alturas de manejo.

\section{Material e Métodos}

O experimento foi realizado em área da Fazenda Nossa Senhora Aparecida, no Noroeste do Estado do Paraná. A área experimental fica próxima à divisa dos municípios de Astorga e Maringá, a 2318'24,79"S, 5151'2,61"W e 405,7 m de altitude. O períodoexperimental foi de 19/12/1998 a 13/5/1999, no total de 146 dias de avaliações. O clima da região é Cw'h, conforme a classificação de Köppen. As temperaturas médias anuais na região variam de 18 a $22^{\circ} \mathrm{C}$, a pluviometria oscila entre 1.000 a $1.500 \mathrm{~mm}$ anuais, com período seco nos meses de julho e agosto (Nery et al., 2002). A precipitação pluvial durante o período experimental foi de $708 \mathrm{~mm}$.
O solo da área experimental é Latossolo Roxo distroférrico argiloso (Embrapa, 1999). A análise de solo apresentou os seguintes resultados: $\mathrm{pH}-\mathrm{H}_{2} \mathrm{O}, 6,9 ; \mathrm{Al}^{3+}$, $0,0 \mathrm{cmol}_{\mathrm{c}} \mathrm{dm}^{-3} ; \mathrm{H}+\mathrm{Al}^{3+}, 3,13 \mathrm{cmol}_{\mathrm{c}} \mathrm{dm}^{-3} ; \mathrm{Ca}^{2+}+\mathrm{Mg}^{2+}$, $7,16 \mathrm{cmol}_{\mathrm{c}} \mathrm{dm}^{-3} ; \mathrm{K}^{+}, 0,60 \mathrm{cmol}_{\mathrm{c}} \mathrm{dm}^{-3} ; \mathrm{P}, 3 \mathrm{mg} \mathrm{dm}^{-3} ; \mathrm{eC}$, $15,96 \mathrm{~g} \mathrm{dm}^{-3}$. A adubação foi feita no final de setembro de 1998, pouco antes da semeadura da pastagem, pela incorporação ao solo de $180 \mathrm{~kg} \mathrm{ha}^{-1}$ de $\mathrm{P}_{2} \mathrm{O}_{5}$ (superfosfato simples) e $60 \mathrm{~kg} \mathrm{ha}^{-1} \mathrm{de}_{2} \mathrm{O}$ (cloreto de potássio). O preparo convencional do solo, por meio de aração seguido de grade niveladora, foi realizado no início de setembro de 1998. A semeadura foi realizada com $10 \mathrm{~kg} \mathrm{ha}^{-1}$ de sementes aplicadas a lanço, incorporadas à profundidade de $1,5 \mathrm{~cm}$ por meio de grade niveladora. A adubação nitrogenada, no total de $250 \mathrm{~kg} \mathrm{ha}^{-1}$ (uréia), foi realizada a lanço e parcelada em quatro aplicações de $40 \mathrm{~kg} \mathrm{ha}^{-1}$ (novembro) antes da entrada nos animais nos piquetes, e de $100 \mathrm{~kg} \mathrm{ha}^{-1}$ (janeiro), $80 \mathrm{~kg} \mathrm{ha}^{-1}$ (fevereiro) e $30 \mathrm{~kg} \mathrm{ha}^{-1} \mathrm{em}$ março. Durante o estabelecimento da pastagem, a área de 8,9 ha foi subdividida em oito piquetes com cercas fixas, com áreas de 1,04 a 1,27 ha. Novilhos da raça Nelore, com idade entre 15 e 18 meses e massa corporal inicial média de $250 \mathrm{~kg}$, foram alocados nas unidades experimentais, quando a altura do pasto atingiu aproximadamente $90 \mathrm{~cm}$. O método de pastejo utilizado foi lotação contínua com taxa de lotação variável (Mott \& Lucas, 1952), para manter a altura do pasto nos piquetes. Uma pastagem de 6 ha, formada com capim-tanzânia, adjacente à área experimental, foi destinada para os animais reguladores.

O delineamento experimental usado foi o inteiramente casualizado, com duas repetições. Os tratamentos foram quatro alturas do pasto: 20, 40, 60 e de $80 \mathrm{~cm}$ (Figura 1),

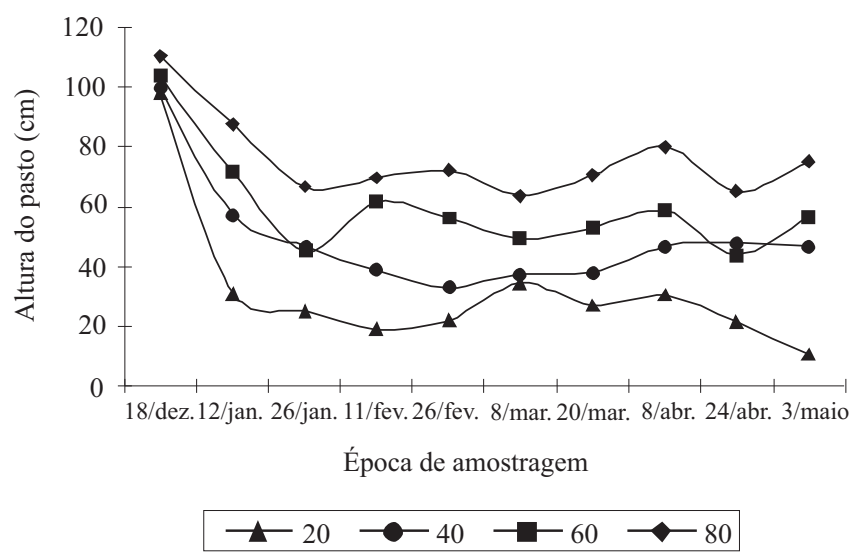

Figura 1. Médias de alturas do pasto, observadas nas pastagens de capim-tanzânia, por época de amostragem. 
e as alturas estimadas nos piquetes foram aproximadamente as mesmas. A altura do pasto foi avaliada por meio de uma régua e realizada de forma aleatória, em cada unidade experimental, com total de 40 leituras. A altura do pasto foi mensurada na extremidade ou na curvatura da folha mais alta que se encostou à régua, a partir do nível do solo.

A massa de forragem foi avaliada por meio da técnica da dupla amostragem (Wilm et al., 1944), e as amostras de forragem foram cortadas ao nível do solo. A equação de Gardner (1986) foi utilizada para o cálculo da quantidade de massa de forragem. Para a estimativa dos componentes morfológicos das plantas, foram colhidas mensalmente seis amostras, em locais que apresentavam altura similar à da unidade experimental. Essas amostras foram cortadas ao nível do solo com tesouras de poda, tendo-se usado uma moldura de ferro com área de $0,25 \mathrm{~m}^{2}$. Essas amostras foram identificadas em sacos de papel, armazenadas em câmaras frias e, posteriormente, secadas em estufa de ar forçado por 56 horas, para a determinação da matéria seca (MS) a $60^{\circ} \mathrm{C}$. Esse procedimento permitiu a avaliação da participação na MS de lâmina de folha verde, de bainha verde, de colmo, de pseudocolmo e de material morto, expressas em grama por quilograma de MS. As frações bainha verde e pseudocolmo foram acrescentadas à fração colmo.

A técnica do triplo emparelhamento, descrita por Moraes (1991), foi usada para a avaliação da taxa de acúmulo de MS, por meio de duas gaiolas de exclusão do pastejo por unidade experimental. Nessa técnica, a cada amostragem, procura-se no pasto duas áreas de vegetação semelhante, para alocação das gaiolas de exclusão de pastejo, e duas áreas fora das gaiolas semelhantes às das gaiolas e entre sí, demarcam-se com estacas de madeira, e realiza-se o corte das áreas demarcadas na avaliação anterior. Os cortes da forragem no interior das gaiolas de exclusão do pastejo e das áreas demarcadas mantidas foras das gaiolas foram realizados em intervalos mensais. A equação de Campbell (1966) foi utilizada para o cálculo da taxa de acúmulo de MS e do acúmulo de MS. As relações entre as variáveis dependentes e as alturas do pasto foram analisadas por equações de regressão. Correlações simples foram realizadas entre a taxa de acúmulo de MS com a massa de forragem, a massa de lâmina de folha verde, a massa de colmo e participação de lâmina de folha, tendo sido considerado o nível de significância de 5\% (SAS Institute, 1986).

\section{Resultados e Discussão}

As alturas do pasto não apresentaram diferença $(\mathrm{p}>0,05)$ quanto à massa de material morto, às proporções na MS de lâmina de folha verde, forragem verde e material morto. Os resultados médios de massa de material morto e das proporções, na MS dos componentes morfológicos, estão mostrados na Tabela 1. Na composição botânica, praticamente se constatou a cultivar Tanzânia-1 durante a realização da dupla amostragem.

A alta participação da MS de forragem verde pode ser atribuída ao fato de os colmos, apesar do aparente amarelecimento, terem sido considerados fisiologicamente ativos e adicionados à fração forragem verde. A participação das lâminas foliares na forragem em oferta, nas situações de altura do pasto avaliadas, pode ser considerada próxima daquelas observadas nos estudos de pastejo de Brâncio et al. (2003), Mello \& Pedreira (2004) e Barbosa et al. (2007). De acordo com Trindade et al. (2007), o manejo do pastejo permite criar ambientes pastoris que favorecem o consumo de componentes morfológicos de alto valor nutritivo.

A relação entre as alturas de manejo do pasto, avaliadas em capim-tanzânia, e a massa de forragem $(\mathrm{CV}=13,16 \%)$, massa de lâmina de folha verde $(\mathrm{CV}=6,09 \%)$, massa de forragem verde $(\mathrm{CV}=5,40 \%)$ e massa de colmo $(\mathrm{CV}=5,04 \%)$ podem ser vistas na Figura 2. O modelo linear positivo foi o que apresentou o ajuste mais satisfatório entre as características de pasto e as alturas do pasto. Foram verificadas quantidades médias de massa de forragem de 2.767 a $4.436 \mathrm{~kg} \mathrm{ha}^{-1}$ de MS, respectivamente, nas alturas de pasto de 20 e $80 \mathrm{~cm}$. Os tratamentos de pastejo condicionaram médias de massa de lâmina de folha verde de 957, 1.223, 1.375 e $1.611 \mathrm{~kg} \mathrm{ha}^{-1}$ de MS, respectivamente, nas alturas de $20,40,60$ e $80 \mathrm{~cm}$.

Tabela 1. Massa de material morto e participação de lâmina de folha verde, de forragem verde e de material morto na matéria seca de pastos de capim-tanzânia, submetidos a diferentes alturas de manejo por bovinos de corte.

\begin{tabular}{ccccc}
\hline $\begin{array}{c}\text { Altura } \\
(\mathrm{cm})\end{array}$ & $\begin{array}{c}\text { Material morto } \\
\left(\mathrm{kg} \mathrm{ha}^{-1}\right)\end{array}$ & $\begin{array}{c}\text { Folhas } \\
\text { verdes } \\
------------------\left(\mathrm{g} \mathrm{kg}^{-1}\right)\end{array}$ & $\begin{array}{c}\text { Forragem } \\
\text { verde }\end{array}$ & $\begin{array}{c}\text { Material } \\
\text { morto }\end{array}$ \\
\hline 20 & 1.125 & 360 & 610 & 390 \\
40 & 800 & 400 & 750 & 260 \\
60 & 912 & 380 & 750 & 250 \\
80 & 1.110 & 360 & 760 & 250 \\
\hline Média & 987 & 380 & 710 & 290 \\
\hline
\end{tabular}


O resultado deste trabalho (Figura 2) e de outros estudos com animais em pastejo demonstram que alturas mais baixas condicionam redução da massa de forragem, ao se usar lotação contínua (Canto et al., 2002) ou intermitente (Carnevalli et al., 2006; Hack et al., 2007). A maior quantidade de massa de forragem, nas maiores alturas de pasto, decorreu do aumento da massa de lâmina de folha verde e da massa de colmo. Em estudo de pastejo com a cultivar Gatton da espécie Panicum maximum, Davison et al. (1985) observaram, no verão, outono e inverno, decréscimo linear da massa de folha verde, à medida que se elevou a taxa de lotação. Devese observar que as quantidades de massa de forragem e de massa de lâminas foliares, relatadas em experimentos de pastejo, podem variar em pastagens mantidas com alturas próximas (Parsons \& Chapman, 2000), em consequiência do manejo, da fertilidade residual do solo, adubações de nitrogênio e demais condições do solo (Hodgson, 1985). Forbes \& Coleman (1993)

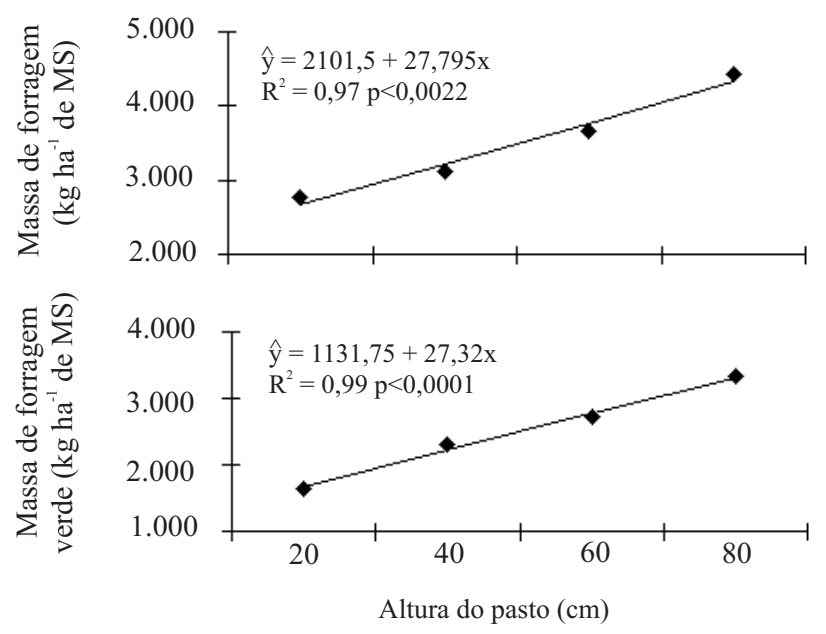

relataram que, nos pastos de inverno, em pastagens de Bothriochloa spp., a manutenção de quantidades de massa de folha verde de $1.000 \mathrm{~kg} \mathrm{ha}^{-1}$ de MS maximizam o consumo de forragem e de matéria orgânica digestível. Em pastagens de capim-elefante anão, usado sob lotação contínua e manejado com ofertas de 3,8, 7,5, 10,5 e $14,7 \mathrm{~kg}$ de MS de lâminas de folhas verdes por $100 \mathrm{~kg}$ de peso vivo (PV) por dia, Almeida et al. (2000b) determinaram as massas de lâmina de folha verde de $722,1.537,2.332$ e de $2.542 \mathrm{~kg} \mathrm{ha}^{-1}$ de MS. As ofertas de 3,8, 7,5,10,5 e 14,7 kg de MS de lâminas de folhas verdes por $100 \mathrm{~kg}$ de PV por dia condicionaram, respectivamente, alturas do pasto de 22, 42,4, 61,4 e de $67,1 \mathrm{~cm}$ (Almeida et al., 2000a).

Os resultados da participação na MS do colmo $(\mathrm{CV}=8,75 \%)$ na massa de forragem e da razão folha:colmo $(\mathrm{CV}=1,51 \%)$ podem ser examinados na Figura 3. A participação da MS de colmo se elevou à

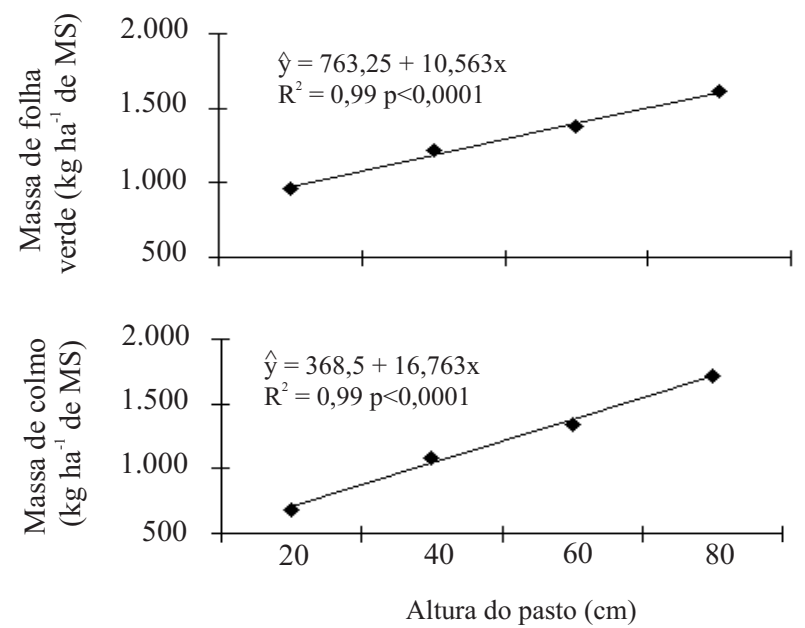

Figura 2. Massa de forragem, massa de lâmina de folha verde, massa de forragem verde e massa de colmo, em pastos de capim-tanzânia submetidos a diferentes alturas de manejo por bovinos de corte.
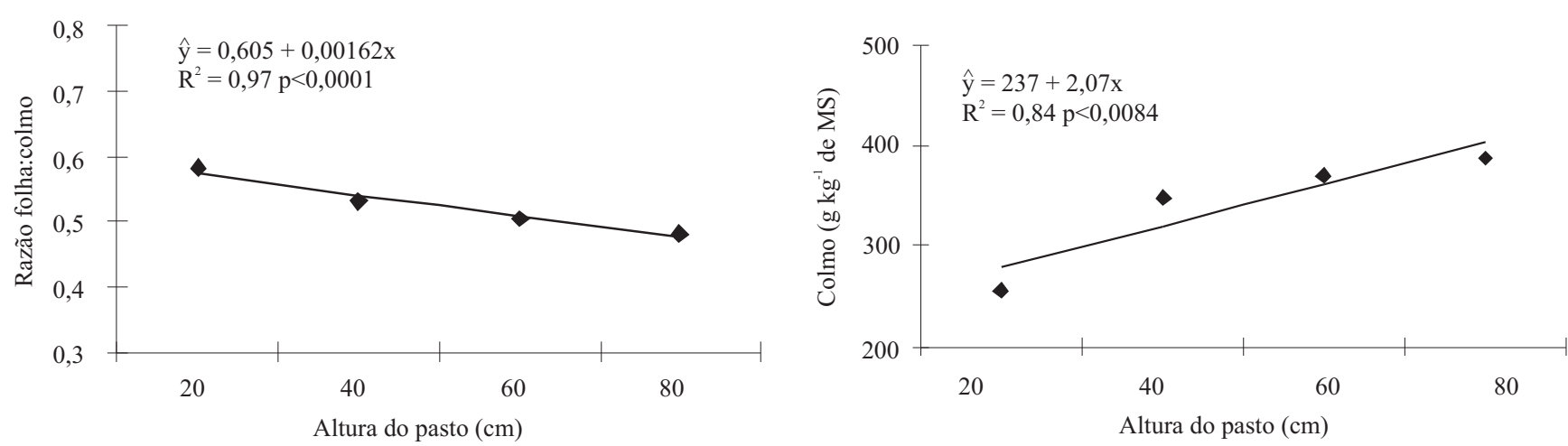

Figura 3. Razão folha:colmo e participação do componente colmo, em pastos de capim-tanzânia submetidos a diferentes alturas de manejo por bovinos de corte. 
medida que a altura do pasto aumentou. O modelo linear negativo foi o que melhor se ajustou à relação da variável razão folha:colmo com as alturas do pasto.

Os tratamentos de pastejo determinaram redução da razão folha:colmo e aumento da participação das hastes na MS, em razão da maior presença de entrenós alongados nas maiores alturas do pasto. O comportamento dessas variáveis mostrou a deterioração da estrutura dos perfilhos, à medida que a altura do pasto se elevou. Pastos manejados com alturas de pasto elevadas e alta densidade de colmos podem restringir a seleção das lâminas foliares pelos animais (Newman et al., 2003). Ressalta-se que, nas pastagens mantidas com a altura do pasto de $20 \mathrm{~cm}$, foram verificadas, ao final do período experimental e em baixas proporções, áreas com solo desnudo e presença das espécies das plantas invasoras guanxuma (Sida urens L.) e assa-peixe (Vernonia ferruginea Less.). Áreas de solo descoberto e de plantas indesejáveis são indícios de degradação de pastos. Em experimento subseqüente a este estudo de pastejo, realizado no inverno, após o diferimento das pastagens no outono, Canto et al. (2001) constataram que, nas alturas de pasto próximas de $20 \mathrm{~cm}$, houve redução do diâmetro de touceiras do capim-tanzânia e aumento das áreas de solo descoberto. A maior presença de hastes, nas pastagens mais altas, pode estar associada ao mecanismo de competição por luz nos estratos folhosos superiores, que interceptam parte considerável da luz incidente, o que pode causar o alongamento dos colmos de forma a dispor as lâminas das folhas no topo dos perfilhos. O início do período reprodutivo, que ocasiona o alongamento dos entrenós, possivelmente contribuiu também para a participação do colmo na MS. No experimento de Carnevalli et al. (2006), realizado em pastos de capim-mombaça sob regime de lotação intermitente, com $100 \%$ de interceptação de luz em prépastejo, observou-se aumento da participação de colmos na MS, na massa de forragem em pré-pastejo e em póspastejo, em comparação à interceptação de $95 \%$. Vale ressaltar que os resultados desses autores foram verificados nos estádios vegetativo e reprodutivo. Hack et al. (2007) compararam, em regime de lotação intermitente, pastos de capim-mombaça usados em duas alturas pré-pastejo, 140 e $90 \mathrm{~cm}$, e duas alturas pós-pastejo, 30 e $50 \mathrm{~cm}$. Os autores mostraram que a altura mais baixa apresentou efeitos favoráveis nas características do dossel e na produção de leite de vacas mantidas exclusivamente sob pastejo. Outro fator que possivelmente influenciou o valor observado de participação das hastes na MS foi o período experimental, que ocorreu, na maior parte, durante a estação do verão. Zeferino (2006) avaliou pastos de capim-marandu (Brachiaria brizantha) e Carnevalli et al. (2006) avaliaram pastos de capim-mombaça e verificaram que no verão é maior o acúmulo de MS de colmo.

A Figura 4 apresenta os valores de taxa de acúmulo de MS (CV =5,78\%) e do rendimento de forragem $(\mathrm{CV}=5,78 \%)$. Observa-se que a regressão linear negativa explicou o efeito do aumento da altura do pasto sobre a taxa de acúmulo de MS e no acúmulo de MS. Os resultados de taxa de acúmulo de MS e de rendimento de forragem, nas alturas do pasto de 40 e $60 \mathrm{~cm}$, foram, respectivamente, de 108 e $90 \mathrm{~kg} \mathrm{ha}^{-1}$ de MS por dia e de 15.695 e $13.067 \mathrm{~kg} \mathrm{ha}^{-1}$ de MS. A correlação entre a taxa de acúmulo de MS e a massa de forragem, a massa de lâmina de folha verde, a massa de forragem verde e a massa de colmo verde foram significativas, com valores de $-0,665(\mathrm{p}<0,0358),-0,724(\mathrm{p}<0,0212),-0,724$ $(\mathrm{p}<0,0137)$ e $-0,786(\mathrm{p}<0,0103)$, respectivamente.
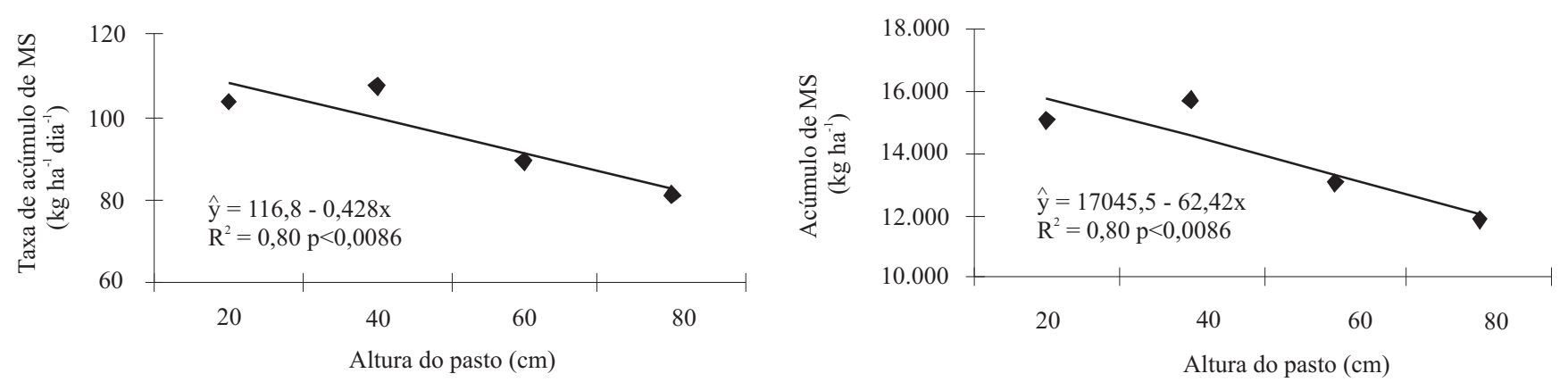

Figura 4. Taxa de acúmulo de matéria seca e acúmulo de matéria seca total, em pastos de capim-tanzânia submetidos a diferentes alturas de manejo por bovinos de corte. 
A correlação da taxa de acúmulo de MS com as participações de lâmina de folha verde e de forragem verde não foram significativas ( $p>0,05$ ).

Silva (2004) mencionou que, o acúmulo de MS em pastos de capim-tanzânia durante a rebrotação, foi maior em condições de $25 \mathrm{~cm}$ de resíduo e, quando o manejo da forrageira teve o objetivo de estabelecer um dossel com 95\% de interceptação luminosa. Possivelmente, no presente experimento, o período usado para o corte da forragem das áreas excluídas, por meio das gaiolas, influenciou em parte a estimativa da taxa de acúmulo de MS. As correlações significativas da taxa de acúmulo de MS com algumas das características do pasto podem ser, também, parcialmente atribuídas ao período usado para o corte da forragem, no interior das gaiolas de exclusão do pastejo. Segundo Parsons et al. (1984), o número de dias usado para a estimativa da taxa de acúmulo de MS pode ocasionar valores subestimados ou superestimados, em decorrência da evolução do índice de área foliar, no interior das gaiolas de exclusão do pastejo. Experimentos com altos rendimentos de MS em pastos de Panicum maximum, em consequiência das melhorias na fertilidade do solo e no manejo, podem ser analisados em Muir \& Jank (2004) e Euclides et al. (2007). Os resultados de taxa de acúmulo de MS, obtidos nos tratamentos de pastejo para o ano do estabelecimento, podem ser considerados elevados. As taxas de acúmulo de MS, obtidas nas alturas de 20 e de $40 \mathrm{~cm}$, foram próximas das verificadas por Carnevalli et al. (2006) em condições de lotação intermitente.

\section{Conclusões}

1. A variação na altura do pasto de capim-tanzânia, em lotação contínua, implica em alterações nas suas taxas de acúmulo de massa de matéria seca e suas características estruturais.

2. Pastagens de capim-tanzânia, em regime de lotação contínua ao final da primavera e durante o verão, usadas em alturas do pasto entre 40 e $60 \mathrm{~cm}$, permitem quantidades adequadas de massa de folha verde, elevadas taxas de acúmulo de matéria seca e restringem os colmos na massa de forragem.

\section{Referências}

ALMEIDA, E.X.; MARASCHIN, G.E.; HARTMANN, O.E.L.; RIBEIRO FILHO, H.M.N.; SETELICH, E.A. Oferta de forragem de capim-elefante anão 'Mott' e a dinâmica da pastagem. Revista Brasileira de Zootecnia, v.29, p.1281-1287, 2000a.
ALMEIDA, E.X.; MARASCHIN, G.E.; HARTMANN, O.E.L.; RIBEIRO FILHO, H.M.N.; SETELICH, E.A. Oferta de forragem de capim-elefante anão 'Mott' e o rendimento animal. Revista Brasileira de Zootecnia, v.29, p.1288-1295, 2000b.

BARBOSA, R.A.; NASCIMENTO JÚNIOR, D.; EUCLIDES, V.P.B.; SILVA, S.C. da;ZIMMER, A.H.; TORRES JÚNIOR, R.A.A. Capim-tanzânia submetido a combinações entre intensidade e frequiência de pastejo. Pesquisa Agropecuária Brasileira, v.42, p.329-340, 2007.

BRÂNCIO, P.A.; EUCLIDES, V.P.B.; NASCIMENTO JÚNIOR, D.; FONSECA, D.M.; ALMEIDA, R.G.; MACEDO, M.C.M.; BARBOSA, R.A. Avaliação de três cultivares de Panicum maximum Jacq. sob pastejo: disponibilidade de forragem, altura do resíduo pós-pastejo e participação de folhas, colmos e material morto. Revista Brasileira de Zootecnia, v.32, p.55-63, 2003.

CAMPBELL, A.G. Grazed pastures parameters. I. Pasture drymatter production and availability in a stocking rate and grazing management experiment with dairy cows. Journal of Agricultural Science, v.67, p.211-216, 1966.

CANTO, M.W.; CECATO, U.; ALMEIDA JÚNIOR, J.; JOBIM, C.C.; AGULHON, R.A.; GAI, V.F.; HOESCHL, A.R.; QUEIROZ, M.F.S. Produção animal no inverno em capim-tanzânia diferido no outono e manejado em diferentes alturas de pasto. Revista Brasileira de Zootecnia, v.31, p.1624-1633, 2002.

CANTO, M.W.; CECATO, U.; PETERNELLI, M.; JOBIM, C.C.; ALMEIDA JÚNIOR, J.; RIGOLON, L.P.; WATFE, E.; BARRIONUEVO, C.V.; NUNES, B.R.F. Efeito da altura do capimtanzânia diferido nas características da pastagem no período do inverno. Revista Brasileira de Zootecnia, v.30, p.1186-1193, 2001.

CARNEVALLI, R.A.; SILVA, S.C. da; BUENO, A.A.O.; UEBELE, M.C.; BUENO, F.O.; SILVA, G.N.; MORAES, J.P. Herbage production and grazing losses in Panicum maximum cv. Mombaça under four grazing managements. Tropical Grasslands, v.40, p.165176, 2006.

DAVISON, T.M.; COWAN, R.T.; SHEPHERD, R.K.; MARTIN, P. Milk production from cows grazing on tropical grass pastures. 1. Effects of stocking rate and level of nitrogen fertilizer on the pasture and diet. Australian Journal of Experimental Agriculture, v.25, p.505-514, 1985.

EMBRAPA. Sistema brasileiro de classificação de solos. Brasília: Embrapa-SPI; Rio de Janeiro: Embrapa-CNPS, 1999. 412p.

EUCLIDES, V.P.B.; COSTA, F.P.; MACEDO, M.C.M.; FLORES, R.; OLIVEIRA, M.P. Eficiência biológica e econômica de pasto de capim-tanzânia adubado com nitrogênio no final do verão. Pesquisa Agropecuária Brasileira, v.42, p.1345-1355, 2007.

FORBES, T.D.A.; COLEMAN, S.W. Forage intake and ingestive behavior of cattle grazing Old World bluestems. Agronomy Journal, v.85, p.808-816, 1993.

GARDNER, A.L. Técnicas de pesquisa em pastagens e aplicabilidade de resultados em sistemas de produção. Brasília: IICA: Embrapa-CNPGL, 1986. 197p.

GONTIJO NETO, M.M.; EUCLIDES, V.P.B.; NASCIMENTO JÚNIOR, D.; MIRANDA, L.F.; FONSECA, D.M.; OLIVEIRA, M.P. Consumo e tempo diário de pastejo por novilhos Nelore em pastagem de capim-tanzânia sob diferentes ofertas de forragem. Revista Brasileira de Zootecnia, v.35, p.60-66, 2006. 
HACK, E.C.; BONA FILHO, A.; MORAES, A.; CARVALHO, P.C.F.; MARTINICHEN, D.; PEREIRA, T.N. Características estruturais e produção de leite em pastos de capim-mombaça (Panicum maximum Jacq.) submetidos a diferentes alturas de pastejo. Ciência Rural, v.37, p.218-222, 2007.

HODGSON, J. The significance of sward characteristics in the management of temperate sown pastures. In: INTERNATIONAL GRASSLAND CONGRESS, 15., 1985, Kyoto. Proceedings. Kyoto: The Science Council of Japan, The Japanese Society of Grassland Science, 1985. p.63-66.

JANK, L. Melhoramento e seleção de variedades de Panicum maximum. In: SIMPÓSIO SOBRE MANEJO DA PASTAGEM, 12., 1995, Piracicaba. Anais. Piracicaba: Fealq, 1995. p.21-58.

MARRIOT, C.A.; CARRÈRE, P. Structure and dynamics of grazed vegetation. Annales de Zootechnique, v.47, p.359-369, 1998.

MELLO, A.C.L.; PEDREIRA, C.G.S. Respostas morfológicas do capim-tanzânia (Panicum maximum Jacq. cv. Tanzânia-1) irrigado à intensidade de desfolha sob lotação rotacionada. Revista Brasileira de Zootecnia, v.33, p.282-289, 2004.

MORAES, A. Produtividade animal e dinâmica de uma pastagem de pangola (Digitaria decumbens), azevém (Lolium multiflorum Lam.) e trevo-branco (Trifolium repens) submetida a diferentes pressões de pastejo. 1991. 200p. Tese (Doutorado) - Universidade Federal do Rio Grande do Sul, Porto Alegre.

MORAES, A.; PELISSARI, A.; ALVES, S.J.; CARVALHO, P.C.F.; CASSOL, L.C. Integração lavoura-pecuária no Sul do Brasil. In: ENCONTRO DE INTEGRAÇÃO LAVOURA-PECUÁRIA NO SUL DO BRASIL, 1., 2002, Pato Branco. Anais. Pato Branco: Cefet-PR, 2002. p.3-42.

MOTT, G.O.; LUCAS, H.L. The design, conduct and interpretation of grazing trials on cultivated and improved pastures. In: INTERNATIONAL GRASSLAND CONGRESS, 6., 1952, Pennsylvania. Proceedings. Pennsylvania: State College Press, 1952. p.1380-1385.

MUIR, J.P.; JANK, L. Guineagrass. In: MOSER, L.E.; BURSON, B.L.; SOLLENBERGER, L.E. (Ed.) Warm-season $\left(\mathbf{C}_{4}\right)$ Grasses. Madison: ASA; CSSA; SSSA, 2004. p.589-621.

NABINGER, C.; MORAES, A.; MARASCHIN, G.E. Campos in Southern Brazil. In: LEMAIRE, G.; HODGSON, J.; MORAES, A.; CARVALHO, P.C.F.; NABINGER, C. (Ed.). Grassland ecophysiology and grazing ecology. Wallingford: $C A B$ International, 2000. p.355-376.
NERY, J.T.; MARTINS, M.L.O.F.; SANT'ANA, J.L.N. Variabilidade da precipitação no Brasil Meridional. Acta Scientiarum: Science and Technology, v.24, p.1687-1695, 2002.

NEWMAN, Y.C.; SOLLENBERGER, L.E.; CHAMBLISS, C.G. Canopy characteristics of continuously stocked limpograss swards grazed to different heights. Agronomy Journal, v.95, p.1246-1252, 2003.

PALHANO, A.L.; CARVALHO, P.C.F.; DITTRICH, J.R.; MORAES, A.; BARRETO, M.Z.; SANTOS, M.C.F. Estrutura da pastagem e padrões de desfolhação em capim-mombaça em diferentes alturas do dossel forrageiro. Revista Brasileira de Zootecnia, v.34, p.1860-1870, 2005.

PARSONS, A.J.; CHAPMAN, D.F. The principles of pasture growth and utilization. In: HOPKINS, A. (Ed.). Grass: its production \& utilization. $3^{\text {th }}$ ed. Oxford: Blackwell Science, 2000. p.31-89.

PARSONS, A.J.; COLLETT, B.; LEWIS, J. Changes in the structure and physiology of a perennial ryegrass sward when released from a continuous stocking management: implications for the use of exclusion cages in continuously stocked swards. Grass and Forage Science, v.39, p.1-9, 1984.

PRACHE, S.; GORDON, I.J.; ROOK, A.J. Foraging behaviour and diet selection in domestic herbivores. Annales de Zootechnique, v.47, p.335-345, 1998.

SAS INSTITUTE. SAS user's guide: statistics. Cary: Sas Institute, 1986. 419p.

SILVA, S.C. da. Fundamentos para o manejo do pastejo de plantas forrageiras dos gêneros Brachiaria e Panicum. In: SIMPÓSIO SOBRE MANEJO ESTRATÉGICO DA PASTAGEM, 2., 2004, Viçosa. Anais. Viçosa: UFV, 2004. p.347-385.

TRINDADE, J.K.; SILVA, S.C.; SOUZA JÚNIOR, S.J.; GIACOMINI, A.A.; ZEFERINO, C.V.; GUARDA, V.D.A.; CARVALHO, P.C.F. Composição morfológica da forragem consumida por bovinos de corte durante o rebaixamento do capimmarandu submetido a estratégias de pastejo rotativo. Pesquisa Agropecuária Brasileira, v.42, p.883-890, 2007.

WILM, H.G.; COSTELLO, O.F.; KLIPPLE, G.E. Estimating forage yield by the double sampling method. Journal of American Society of Agronomy, v.36, p.194-203, 1944.

ZEFERINO, C.V. Morfogênese e dinâmica do acúmulo de forragem em pastos de capim-marandu (Brachiaria brizantha (Hochst. ex A. Rich.) cv. Marandu) submetidos a regimes de lotação intermitente por bovinos de corte. 2006. 193p. Dissertação (Mestrado) - Escola Superior de Agricultura Luiz de Queiroz, Piracicaba.

Recebido em 8 de agosto de 2007 e aprovado em 18 de março de 2008 